\title{
التحليل البنائي والوصفي \\ لتصميم الأثاث في ظل مدارس التصميم الحديثة
}

إعلداد

أ / غادة بنت محمد صالح عبد الوهاب ناضير.

مجلة بحوث التربية النوعية - جامعة المنصورة

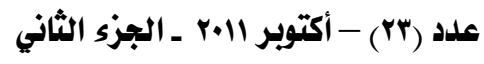




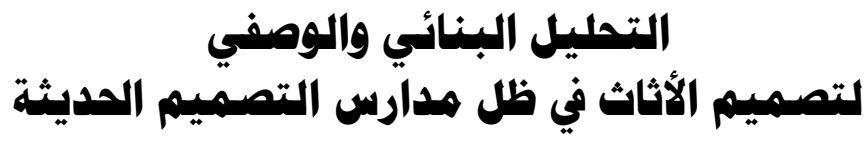

إعداد

الباحثة / غادةبنت محمد صالح عبد الوهابناضريز

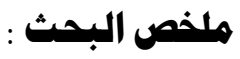

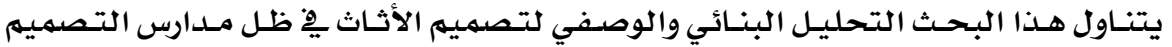

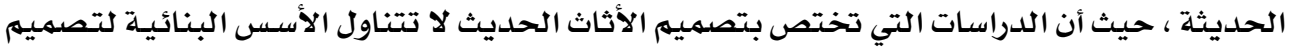

الأثاث الحديث والتعرف على خاماته وخصائص كل خامة ومدى ملائمتها للبيئة السعودية .

ويهدف البحث إلى التعرف على الأسس البنائية لبعض تصاميم الأثاث الحسديث وخاماتها ،

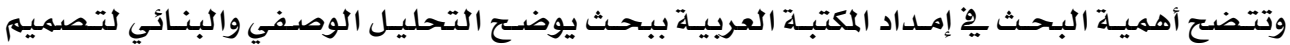

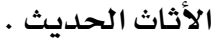

أما فروض البحث فهي : إم إمكانية اعتماد الأشكال البنائية على تجريد التكوينات الهندسية

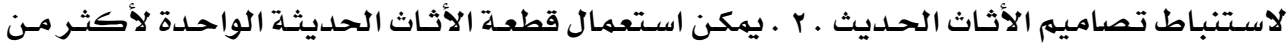

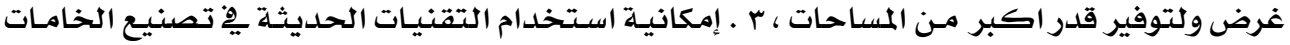

الصناعية . الصنوفير.

وتتبـع هذه الدراسـة المنهج الوصفي التحليلي ، القائم على وصف الظاهرة ، وجــــع المعلومـات

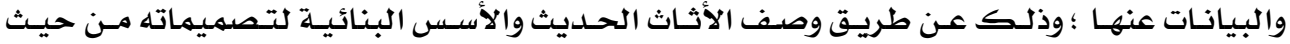

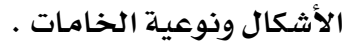

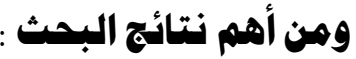

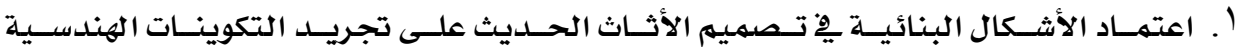

لاستنباط تصاميم متنوعة وبسيطة لقطع الأثاث .

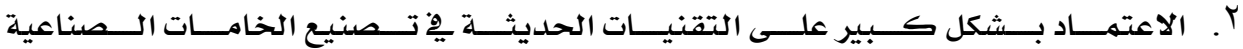

كالأنواع المتعددة من الخشب الصناعي .

وهن أهم توصيات البحث :

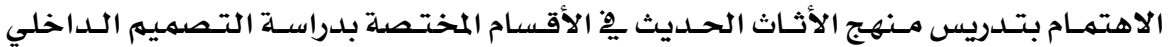

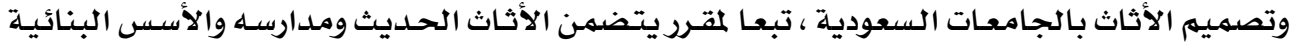

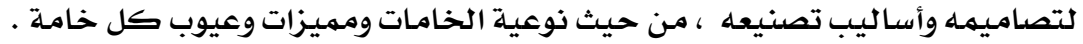




\section{Abstract}

This paper deals with the structural and descriptive analysis for designing the furniture in the light of the schools of modern design. However, the studies which specialize in modern furniture design do not address the structural basis for the design of modern furniture and to identify the raw materials and their characteristics of each. It is also dealing with the applicability of these raw materials in the Saudi environment. This research aims at identify the structural basis for some modern furniture designs. The significance of this research appears in providing the Arab library with a research that demonstrates descriptive analysis and structural for modern furniture design.

\section{As for the hypotheses made for this research, they are as follows:}

1. There is a possibility for the structural shapes to depend on the strip of engineering formations to come up with designs of modern furniture.

2. A piece of modern furniture can be used for more than one purpose in order to provide greater space.

3. There is a possibility for using modern technologies in making industrial raw materials.

This study follows the descriptive analytical method which is based on the phenomenon description, and the collection of the data information related to it. This will be done through the description of modern furniture and structural foundations for the designs in terms of shapes and quality materials.

\section{The main search results:}

1. The structural shapes in the design of modern furniture depend on the strip of engineering formations in order to develop a variety of designs and simple pieces of furniture.

2. The new technology is greatly relied on with regard to manufacturing industrial raw materials such as the various types of industrial wood.

\section{Recommendations of the research:}

It is recommended that there is an interest in the teaching modern furniture in the departments specialized in the study of interior design and furniture design in Saudi universities. In the meantime, it is recommended that the curriculum taught should contain modern furniture, its approaches, designing principles, and the methodologies of making such designs. This should also consider quality of raw materials in terms of advantages and disadvantages of each accordingly 


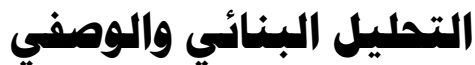

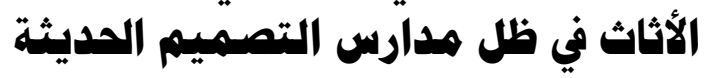

إعداد

الباحةة /غادة بنت محمد صالح عبد الوهابناضربز

الاقدمهة :

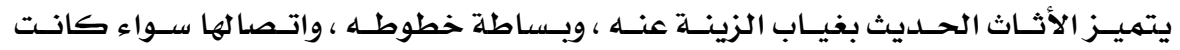

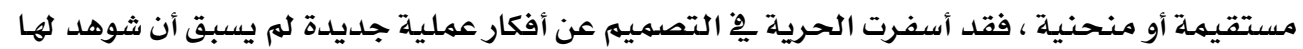

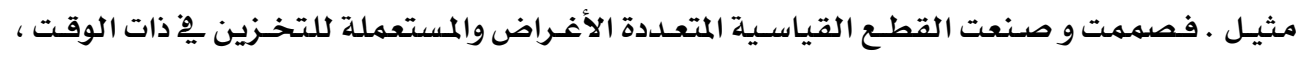

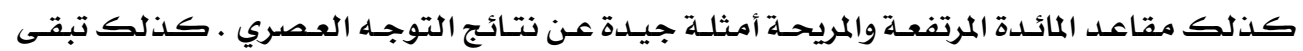

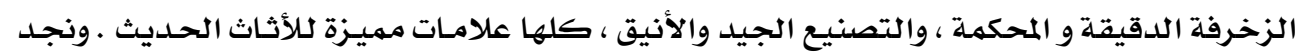

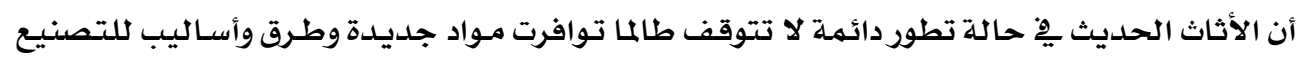

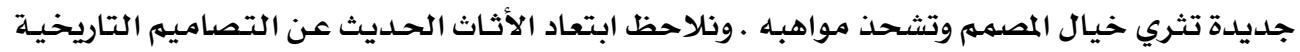

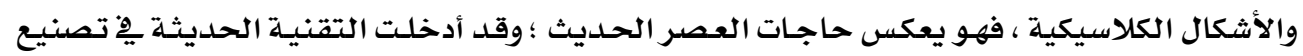

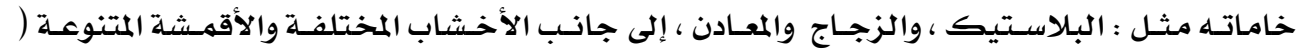

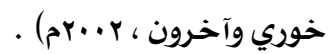

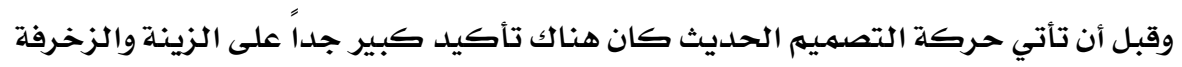

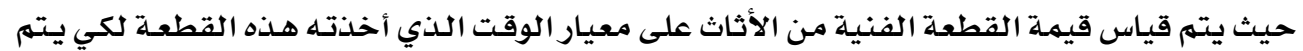

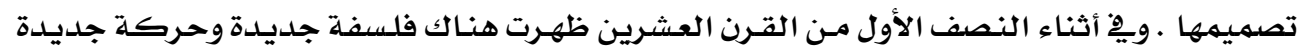

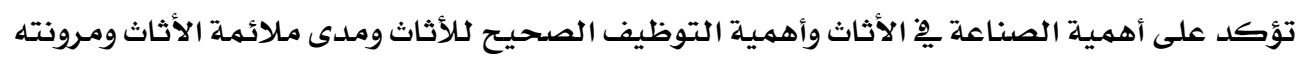

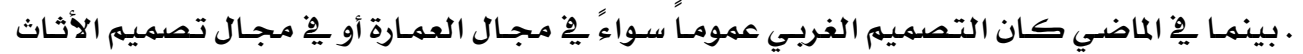

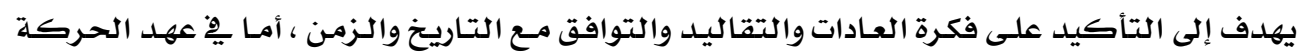

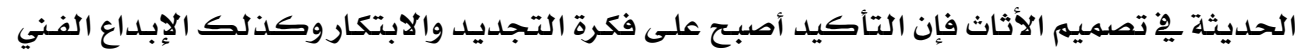

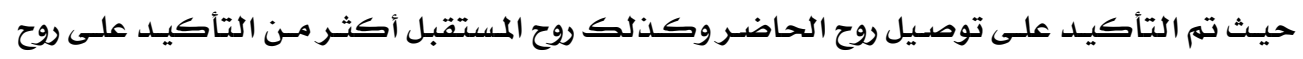

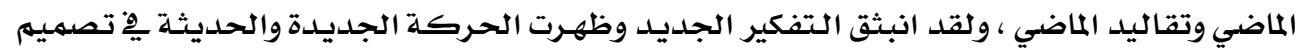

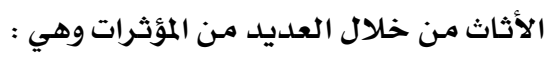

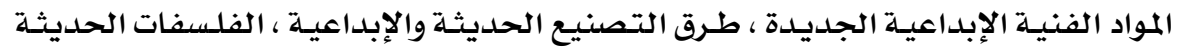

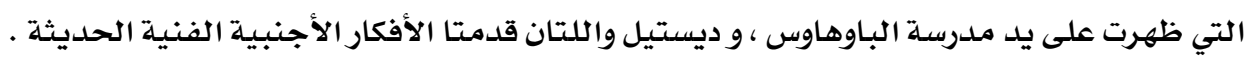
www.torontomodernfurnitures.com/Toronto_Furniture/Origin_modern_f urniture.html r. - $k$ - 
إن الدراسات التي تختص بتصميم الأثاث الحديث لا تتناول الأسس البنائية لتصميم الأثاث

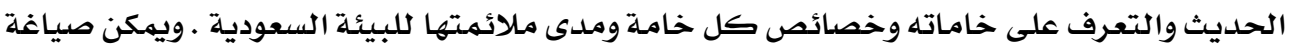

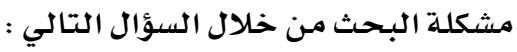

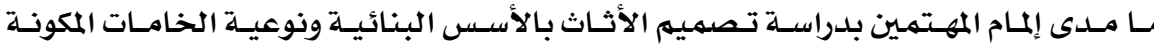
لتصميم الأثاث ؟ مام المام

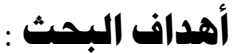
التعرف على الأسس البنائية لبعض تصاميهم الأثاث الحديث وخامـاتها .

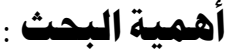
إمداد المكتبـة العربية ببحث يوضح التحليل الوصفي والبنائي لتصميم الأثاث الحديث . فروض البمث : ' . إمكانية اعتماد الأثكال البنائية على تجريد التكوينات الهندسية لاستنباط تصاميم الأثاث

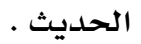

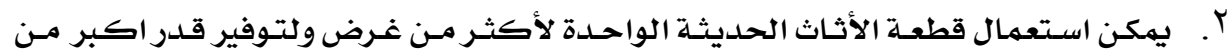
المساحات .

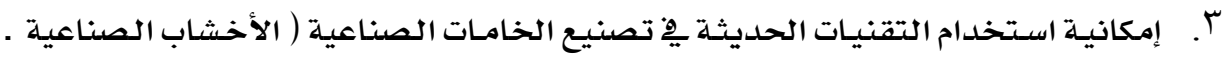

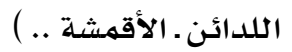

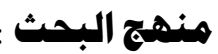

تتبع هذه الدراسـة المنهج الوصفي التحليلي ، القائم على وصف الظـاهرة ، وجـهـع المعلومـات

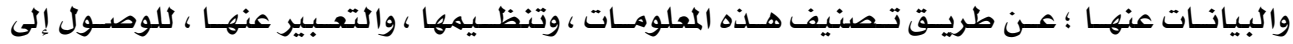

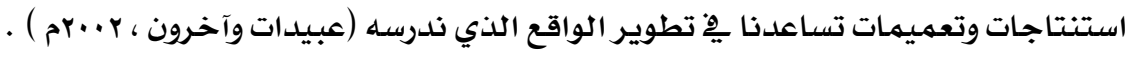

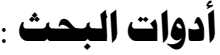

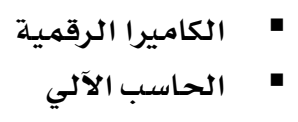
همطالمات الب التصميي Design

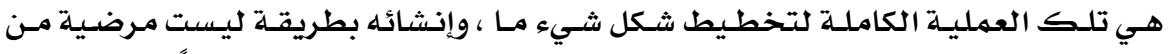

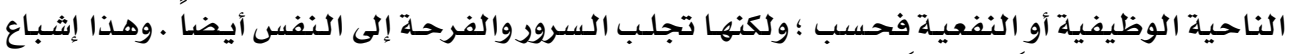

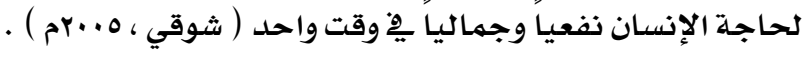




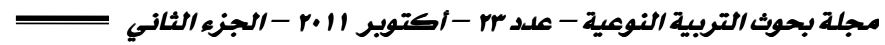

\section{: Modern Furniture الأثثاث الحديث}

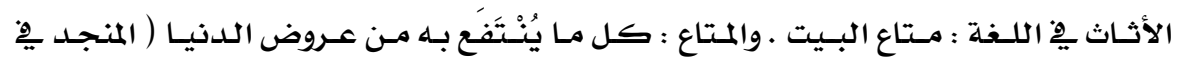

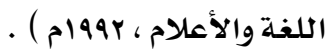

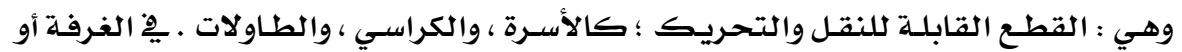

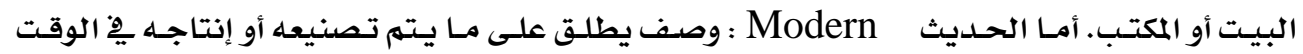

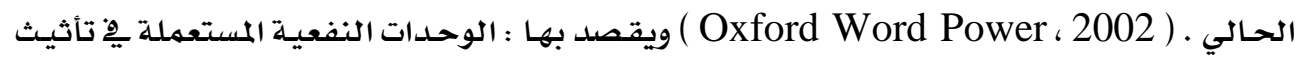
المنزل ( كرسي ، طاولة ، دولاب ... الخ ) . الخامـة (Material)

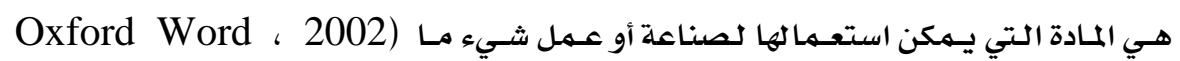

. ( Power

\section{الإطار النظري أولًَ : الأثثاث الحثلث :}

ظهر الأثاث الحديث نتيجة لظهور مدارس التصميم التي أثرت على أسـاليب تصميم الأثاث ولعل أهمها : مالمان

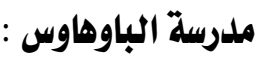

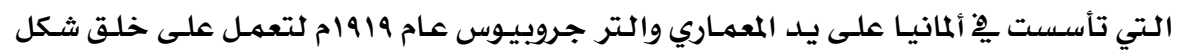

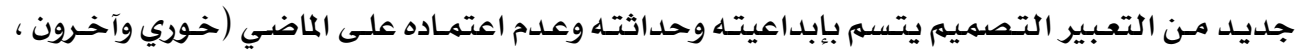
. ( $)$ r...r

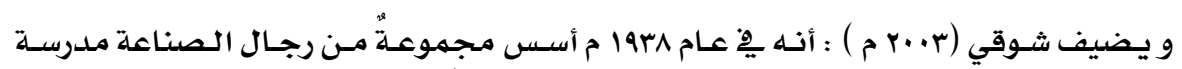

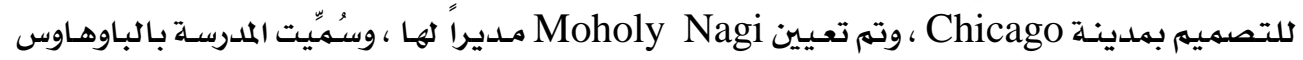

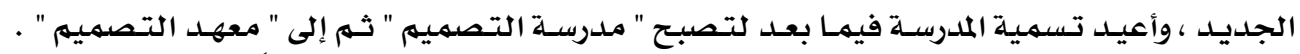

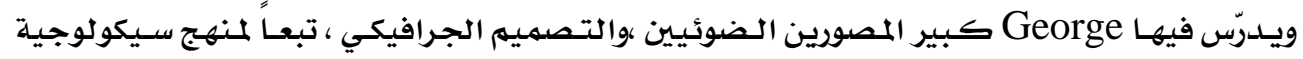

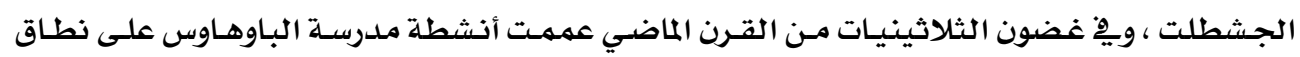

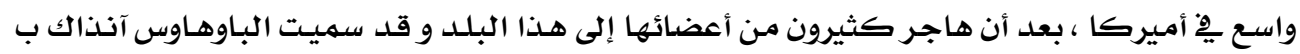

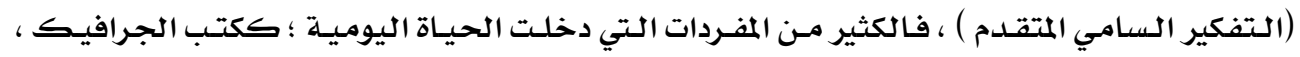

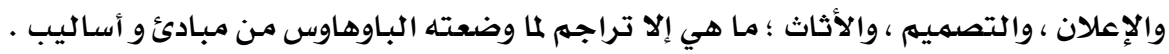

$$
\text { وتبعت هذه المدرسـة حركات مدارس فنية أخرى مثل : }
$$

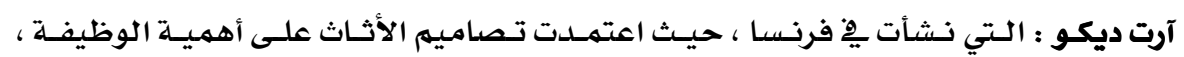

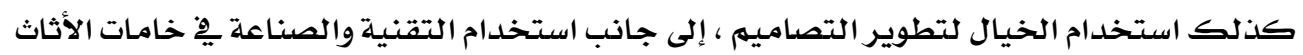

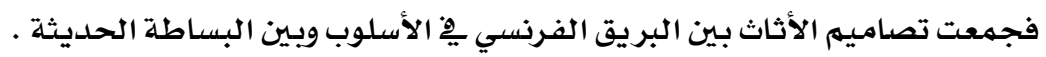




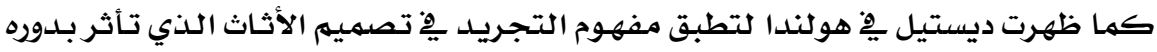

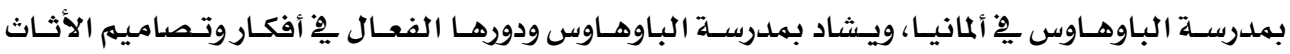

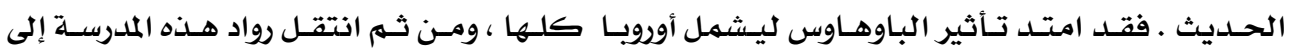

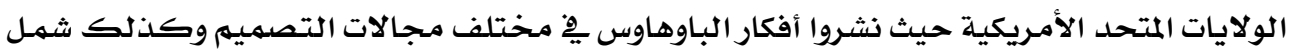
تصميم الأثاث .

www.paksnwifurniture.com/history.htm $17-k$

وقبل أن تأتي حركة التصميمات الحديثة يِّ الأثاث كانت النماذج والأثكال الأكثر شهرة

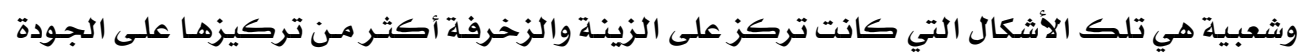

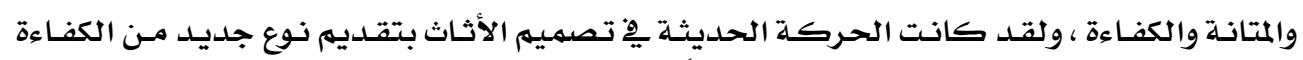

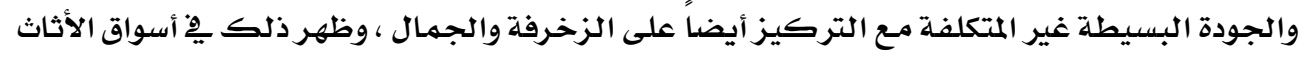

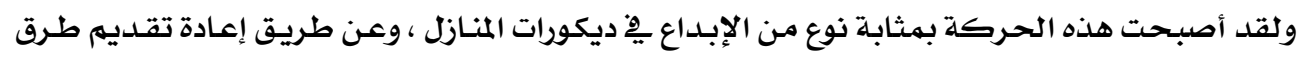

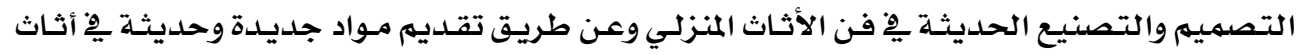

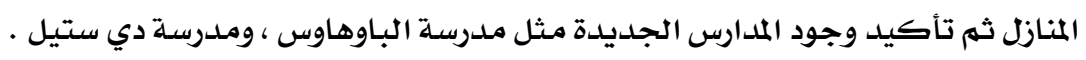
www.squidoo.com/moderndecor $\leqslant 9-k$

ثانياً : الخامات المستخدمة في الأثثاث الحلديث :

كان من أهداف المدارس الفنية الحديثة الجمع بين الفن ، وبين التصميم الصناعي ؛ لإنتاج

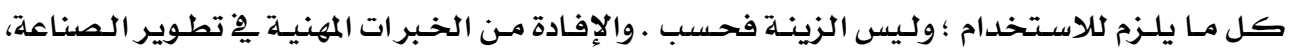

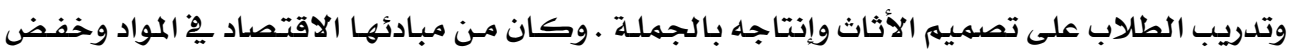

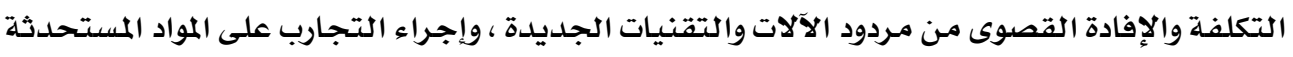

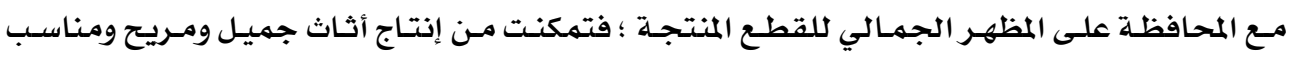

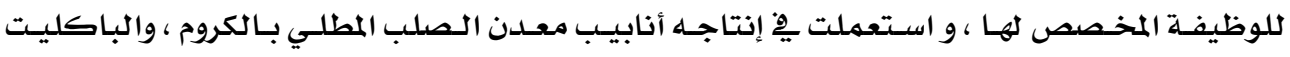

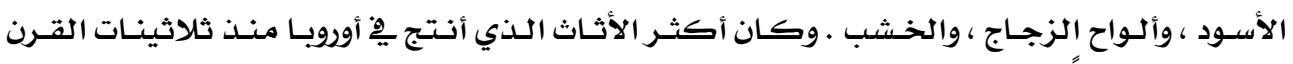

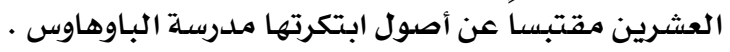
www.arab-ency.com/index.php? module = pnEncyclopedia \&func=display_term \&id=14343$285 k$

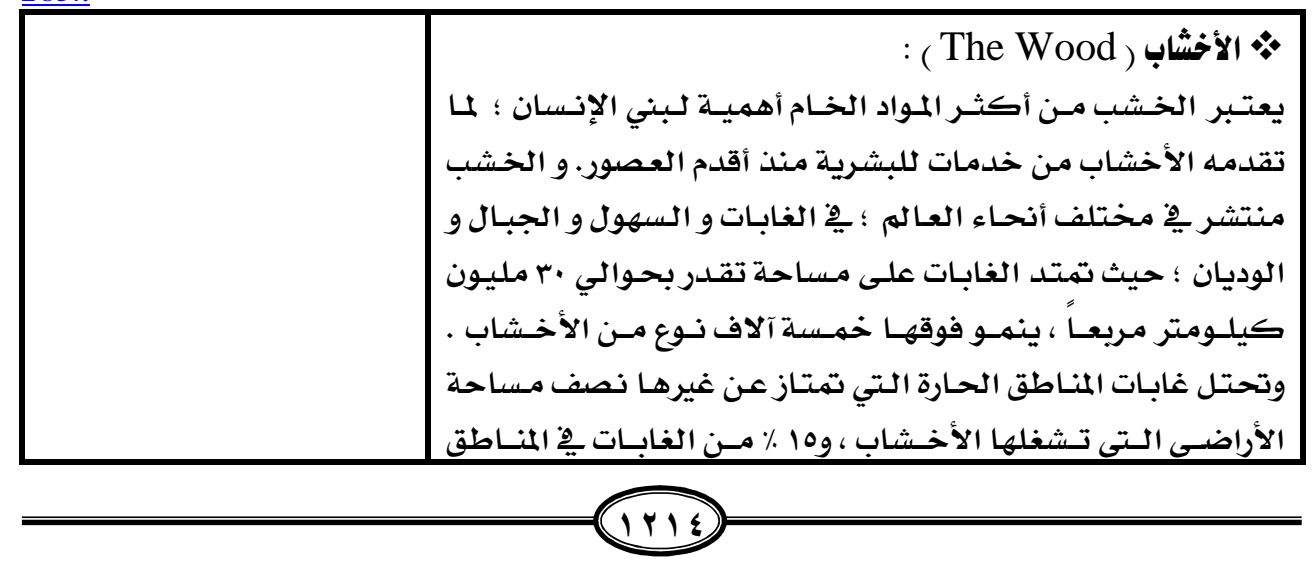




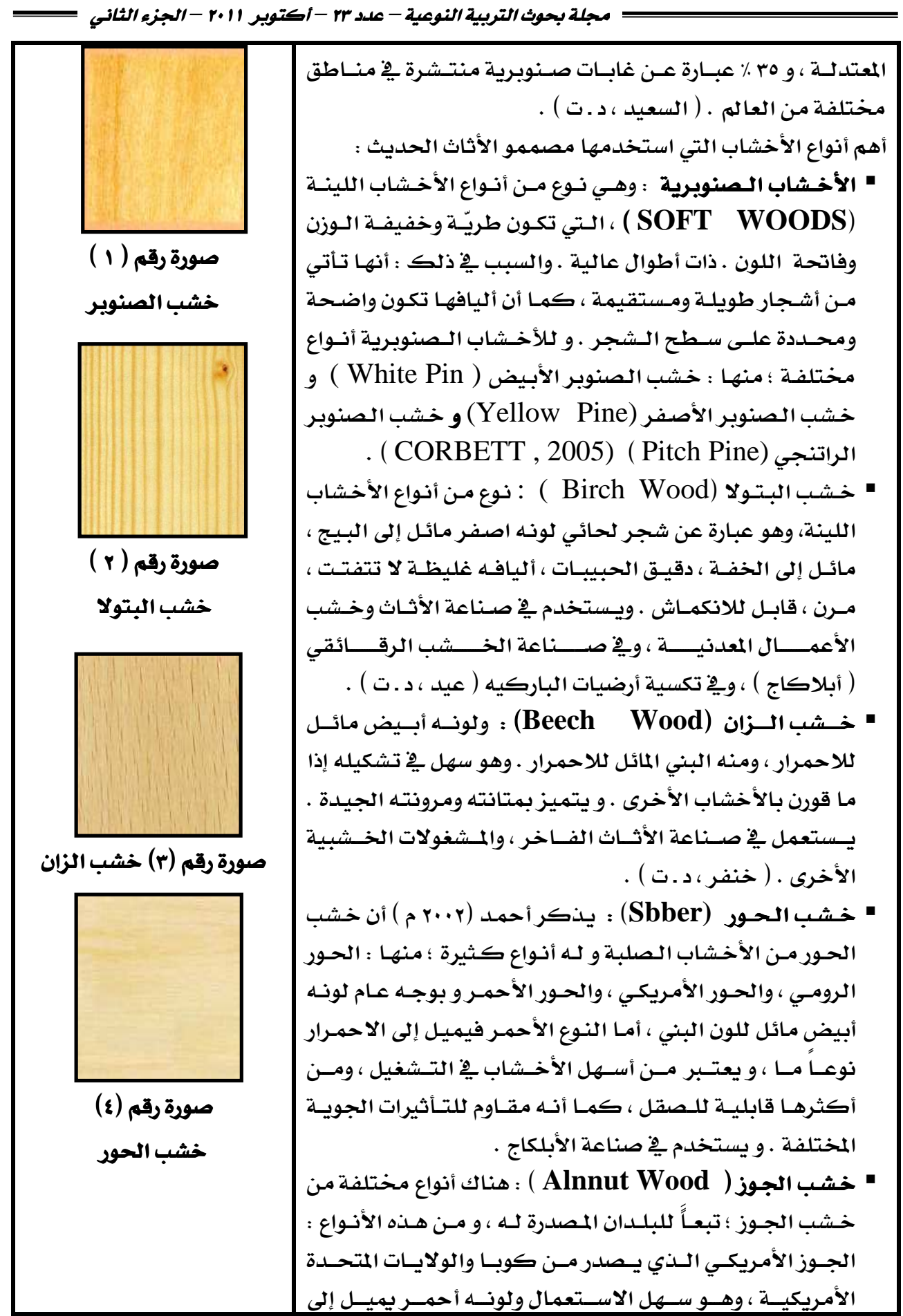




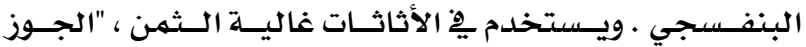

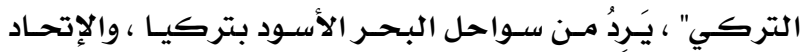

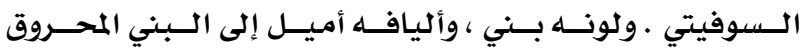

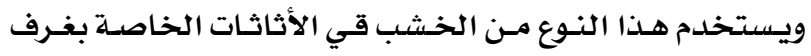

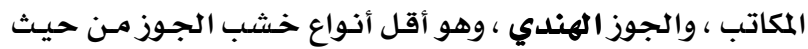

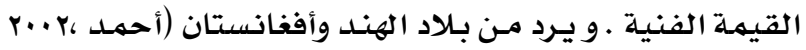

صورة رقم (0) خشب الجوز

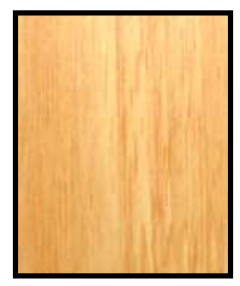
" الأخشاب المصنعة (Wood Manufactured)

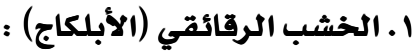

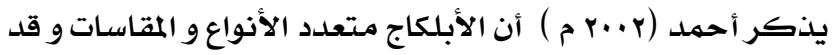

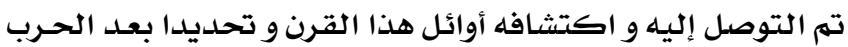

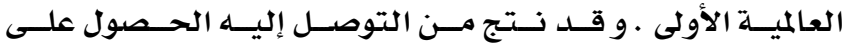

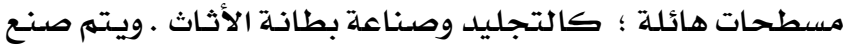

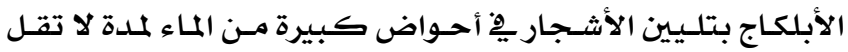

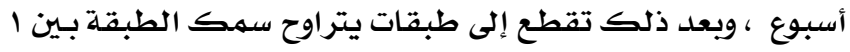
صورة رقم (7) خشب الأبلكاج

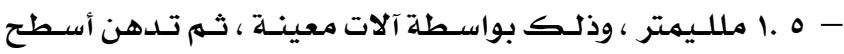

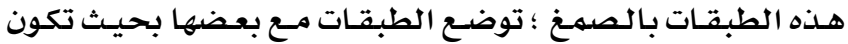

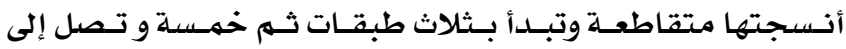

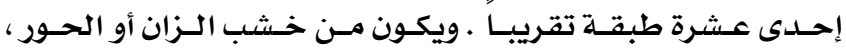

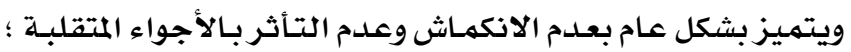

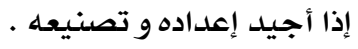

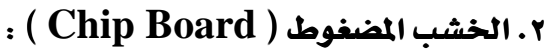

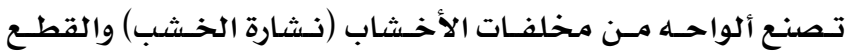

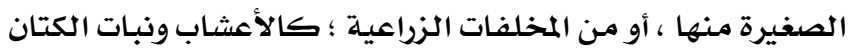

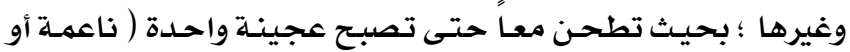

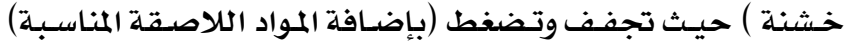
معـا تحست ضغوط مـرتفعـة و درجـات حسرارة عاليـة ؛ لتصبـح ألواحسا

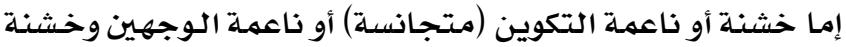

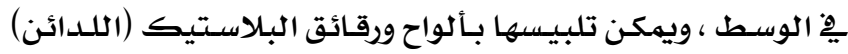

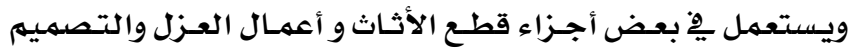

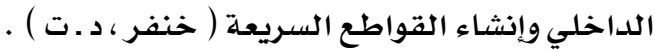
" ثانيا : اللدائن (plastic) :

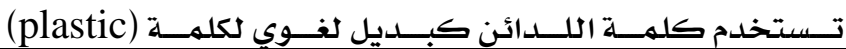




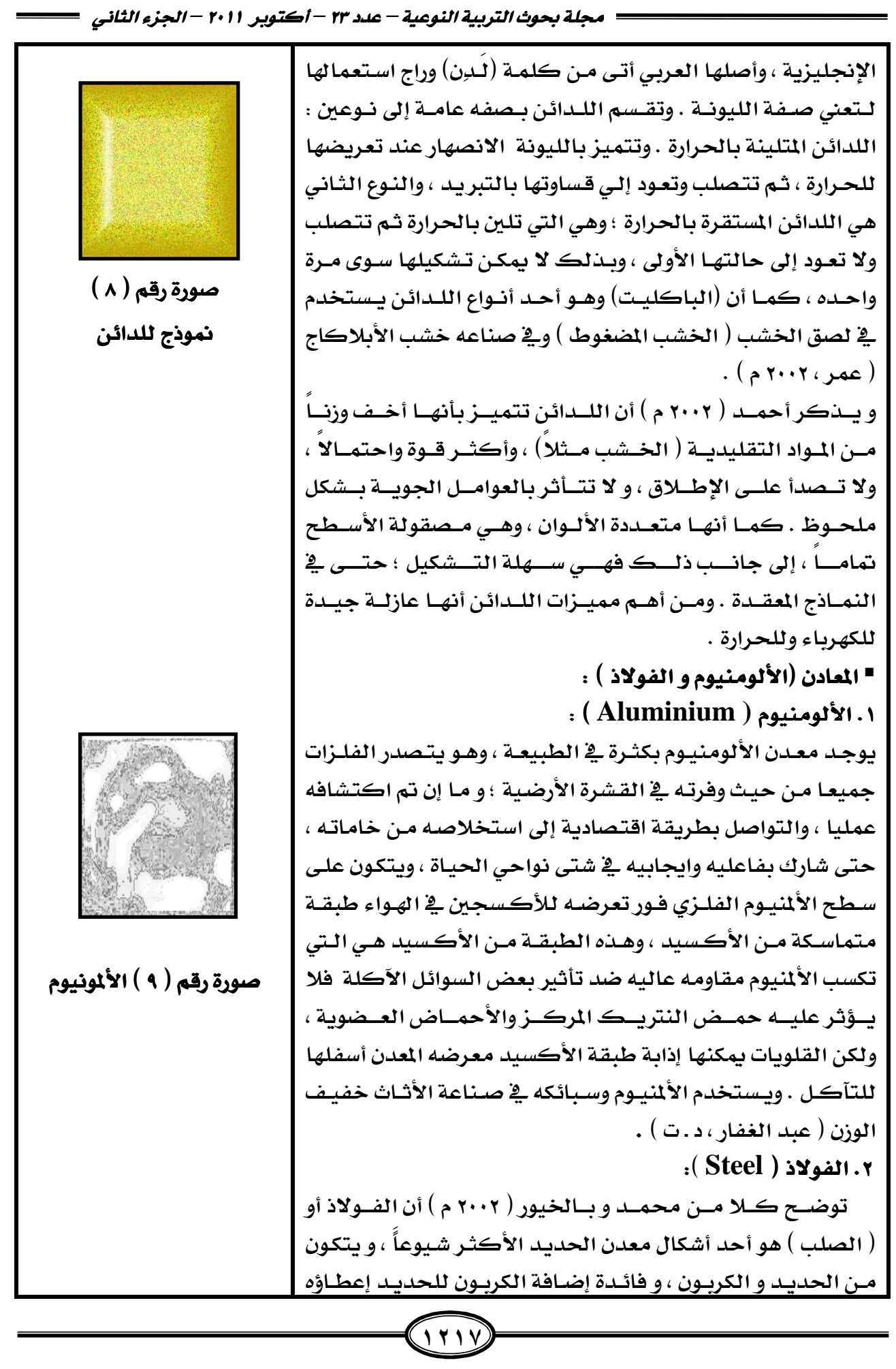


المتانـة و الـصلابة ، إلا انـه قابـل للـصدأ و لـذلك تعـالج منتجاتـه

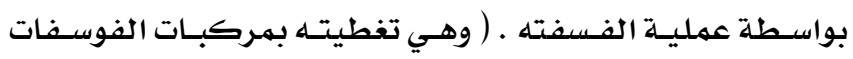

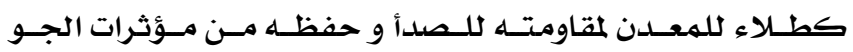

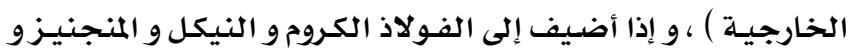

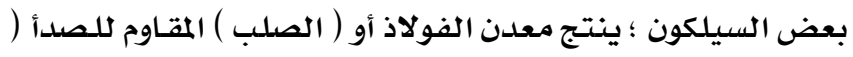

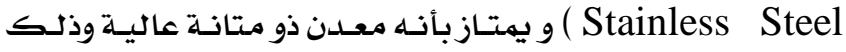
صورة رقم ( •1 ) الفولاذ

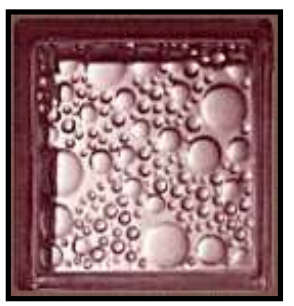

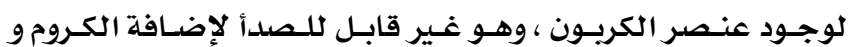

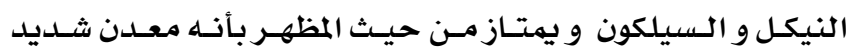

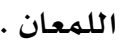

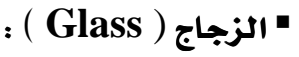

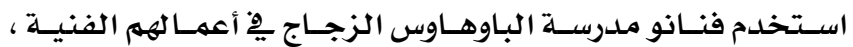
وأشهر مثال على ذلك ما قام بـ "Albers" مـ من تصاميهم و لوحسات

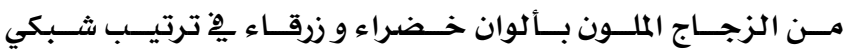

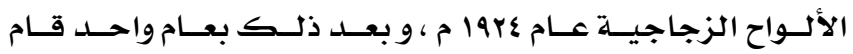

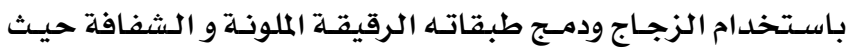

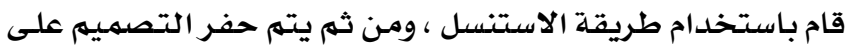

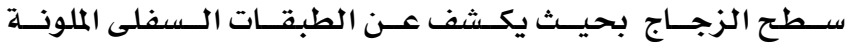
صورة رقم (11) الزجاج

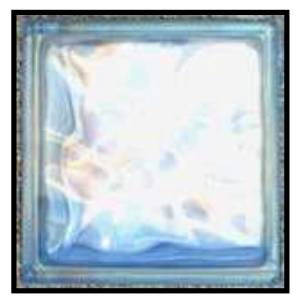
(http://query.nytimes.com/gst/fullpage.html) ويُعرِّف القيسي ( r.r م ) الزجـاج مـن قـاموس "أكسفورد" بأنه :

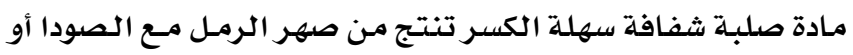

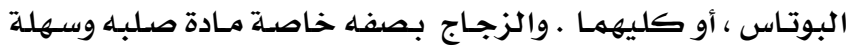

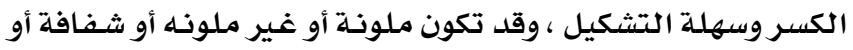

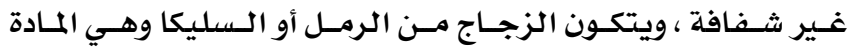

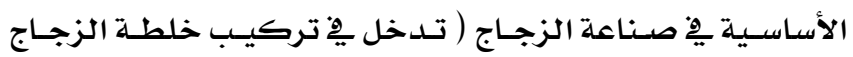

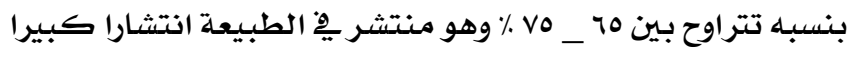
صورة رقم (r ) الزجاج

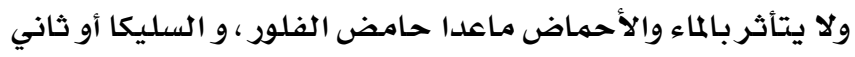

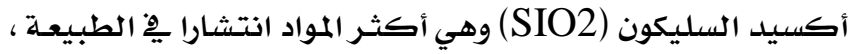

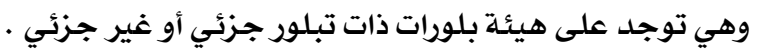

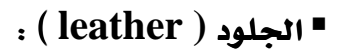

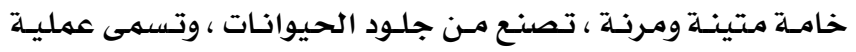

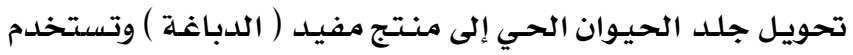

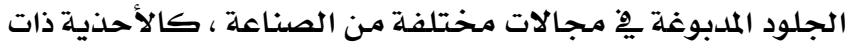

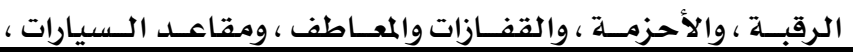




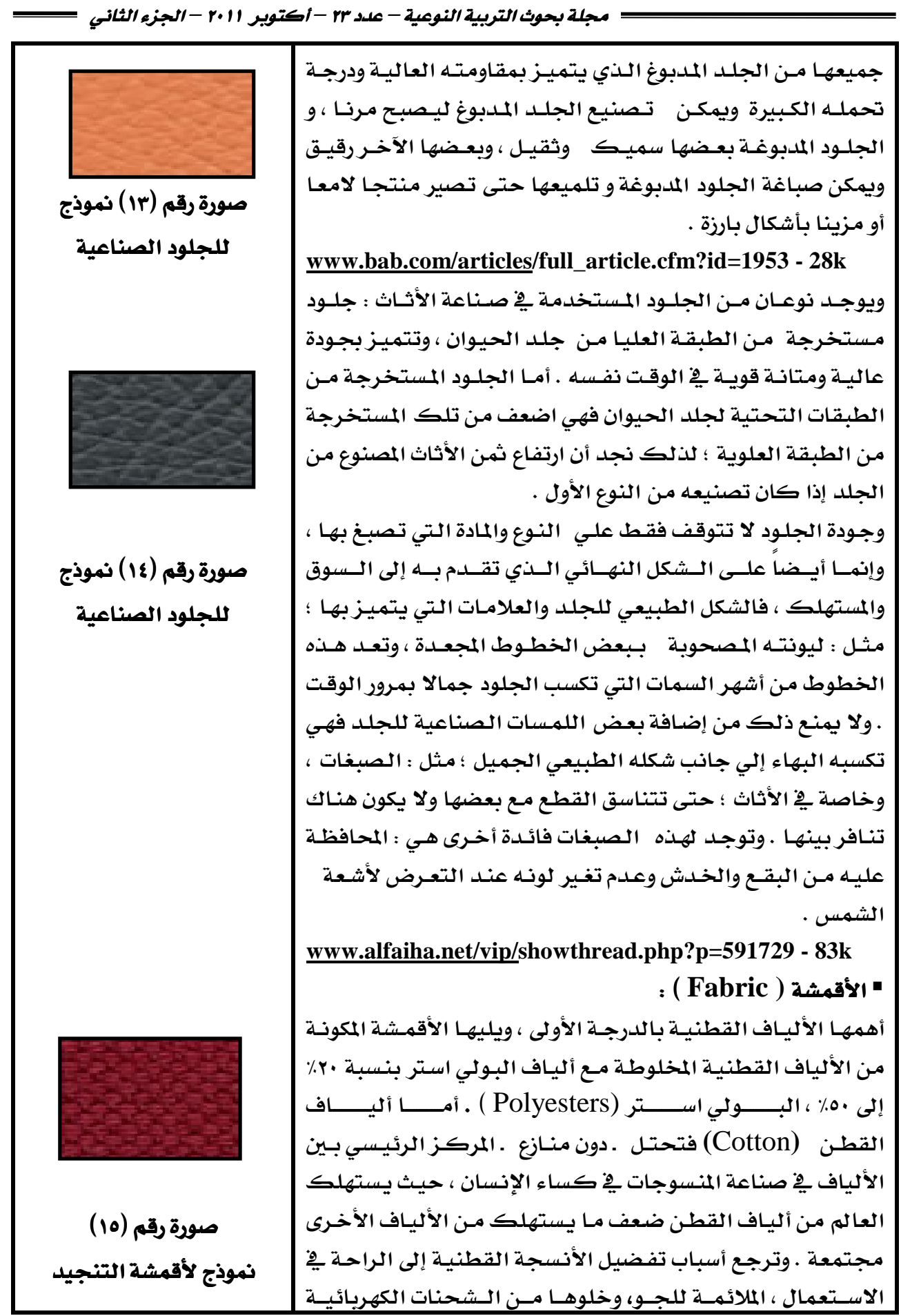




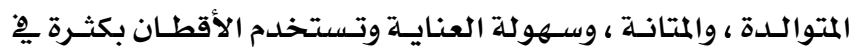

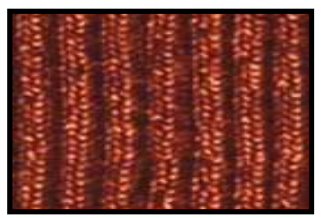

صورة رقم (17) نموذج

لأقمشة التنجيد المفروشات والسجاد ، ويِّ أغراض التنجيد المنزلية .

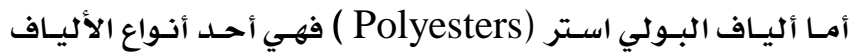

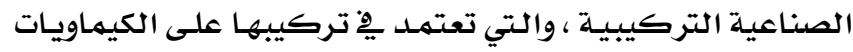

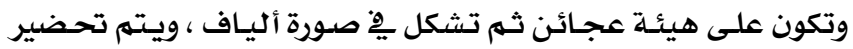

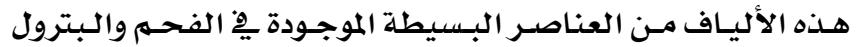

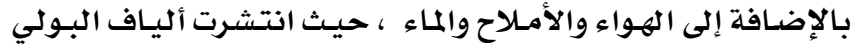

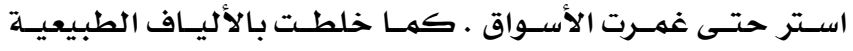

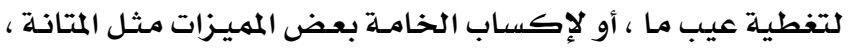

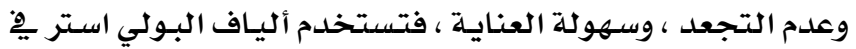

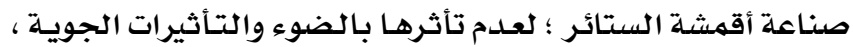

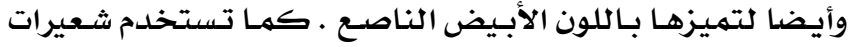

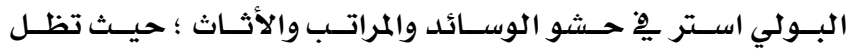

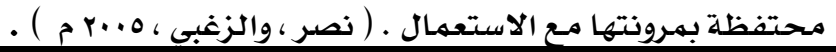

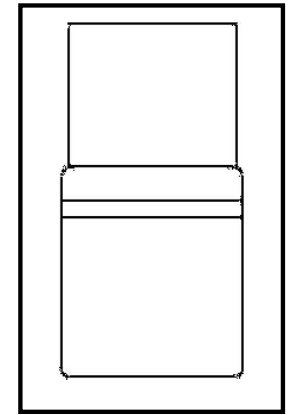

الشكل البنائي

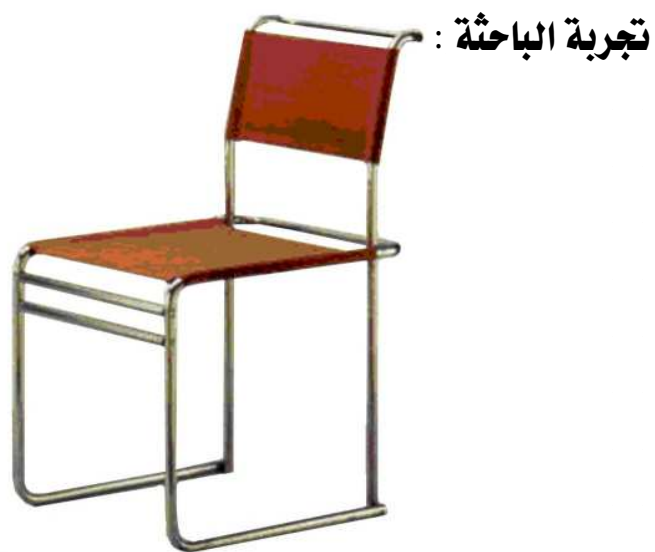

صورة رقم (iv)

المرجع:

\begin{tabular}{|c|c|}
\hline كرسي & ا الشكل \\
\hline معدن ( فولاذ ) - قماش & الخامة \\
\hline 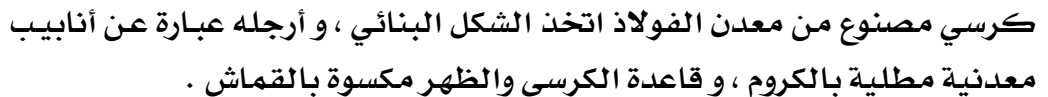 & التوصيف \\
\hline
\end{tabular}



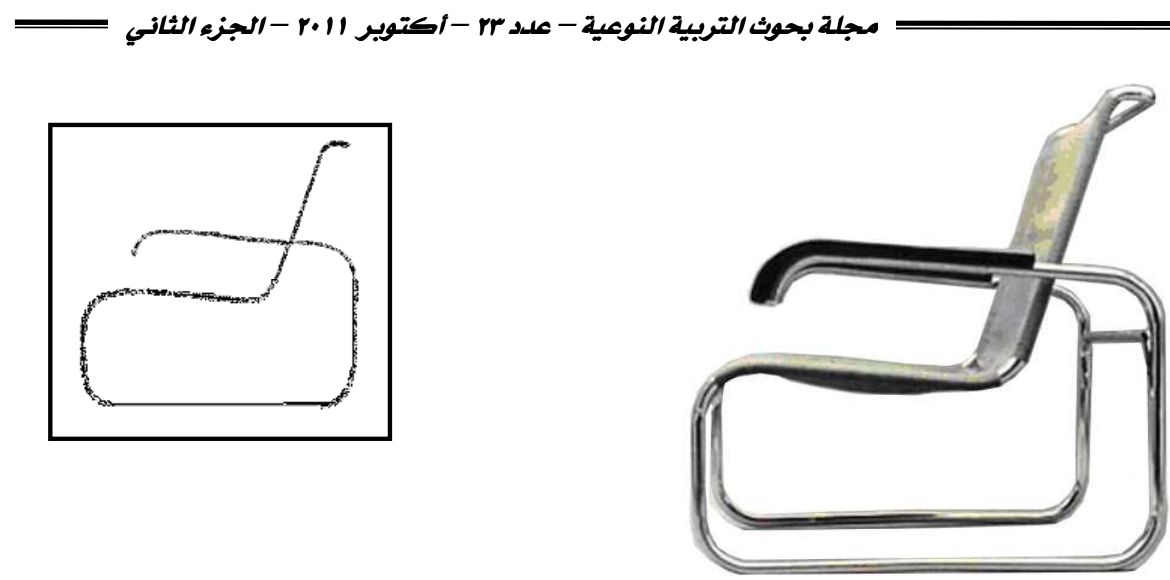

$$
\begin{aligned}
& \text { الشكل البنائي } \\
& \text { صورة رقم (1) }
\end{aligned}
$$

\begin{tabular}{|c|c|}
\hline كرسي & الشكل \\
\hline معدن ( فولاذ ) . جلد & الخامة \\
\hline 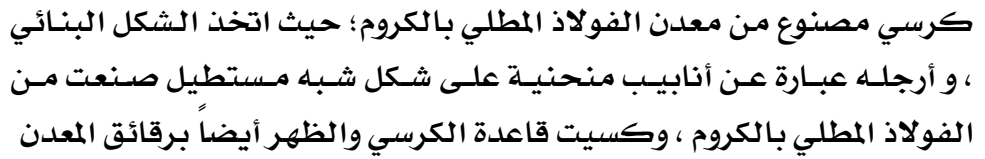 & التوصيف \\
\hline
\end{tabular}

http://www.designmuseum.org/design/marcel-breuer : المرجع

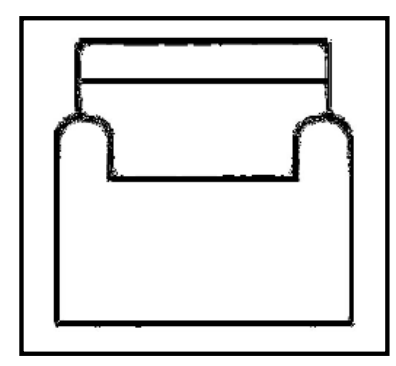

الشكل البنائي

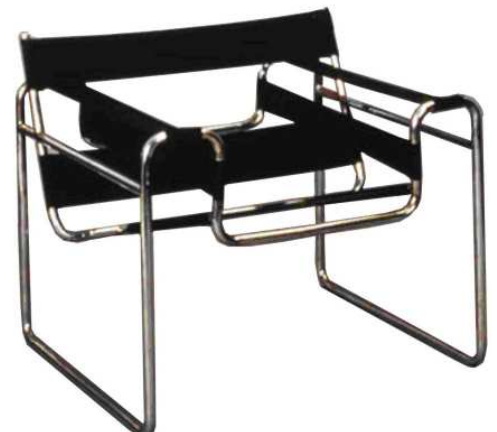

صورة رقم (19)

\begin{tabular}{|c|c|}
\hline كرسي & الشكل \\
\hline معدن ( فولاذ ) & الخامـة \\
\hline 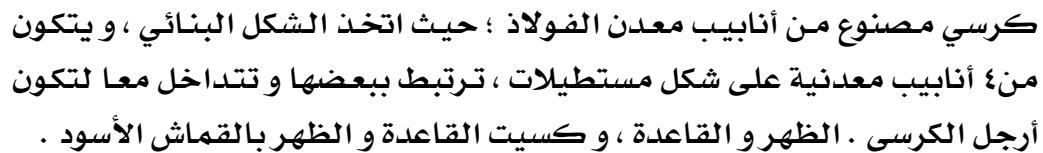 & التوصيف \\
\hline
\end{tabular}

http://www.designmuseum.org/design/marcel-breuer : المرجع 


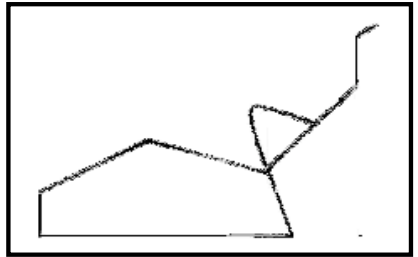

الشكل البنائي

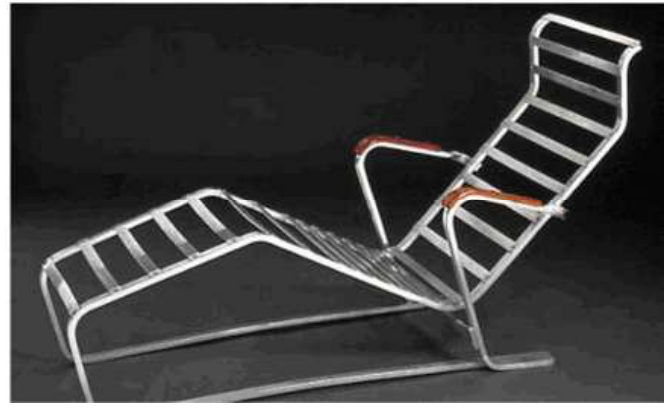

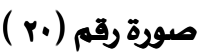

http://www.designmuseum.org/design/marcel-breuer : المرجع

\begin{tabular}{|c|c|}
\hline كرسي & ا الشكل \\
\hline معدن ( ألومينيوم ) ـ لدائن & الخامة \\
\hline 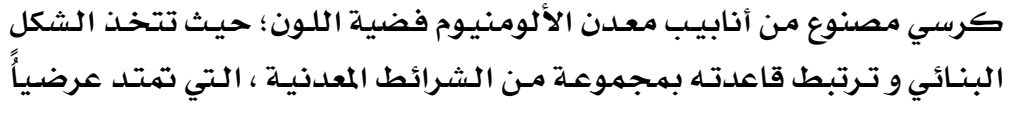 & التوصيف \\
\hline بشكل متتواز . & \\
\hline
\end{tabular}

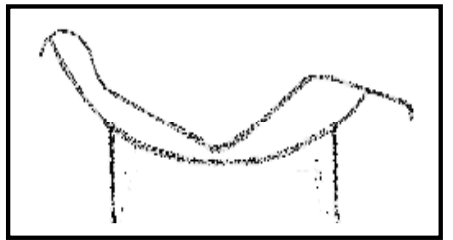

$$
\text { الشكل البنائي }
$$

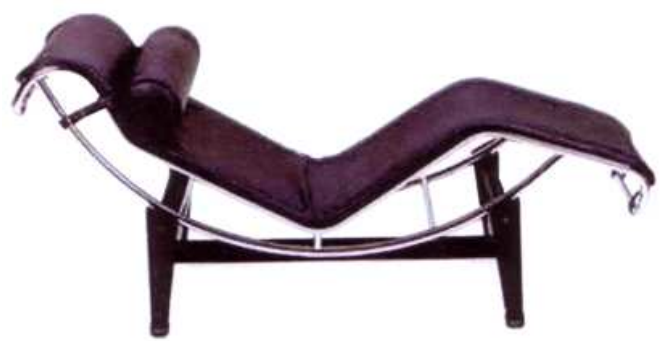

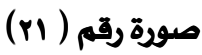

المرجع : ( John , 2005 )

\begin{tabular}{|c|c|}
\hline كرسي & الشكل \\
\hline معدن ( ألومينيوم ) - جلد & الخخامة \\
\hline 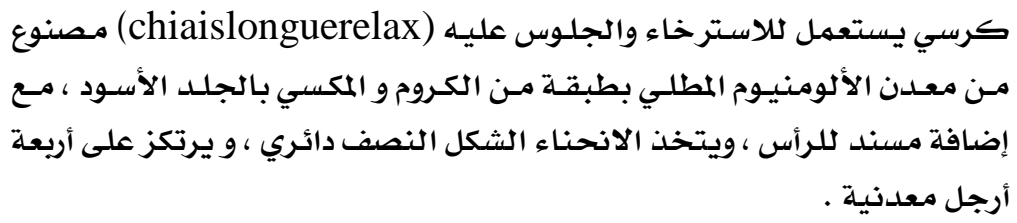 & التوصيف \\
\hline
\end{tabular}




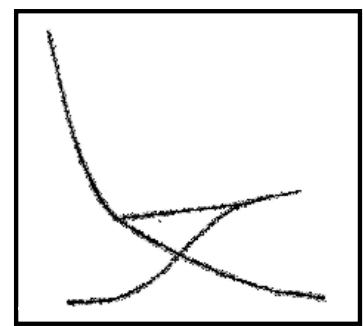

الشكل البنائي

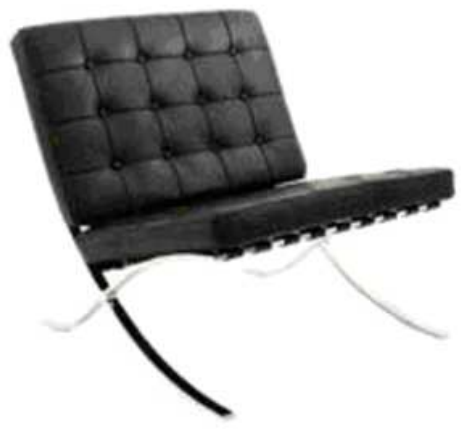

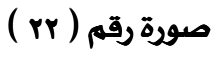

http://www.spacifay.com : المرجع (rr

\begin{tabular}{|c|c|}
\hline كرسي & الشكل \\
\hline معدن ( فولاذ ) - جلد & الخخامة \\
\hline 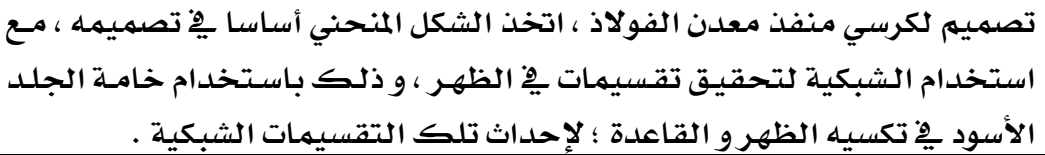 & التوصيف \\
\hline
\end{tabular}
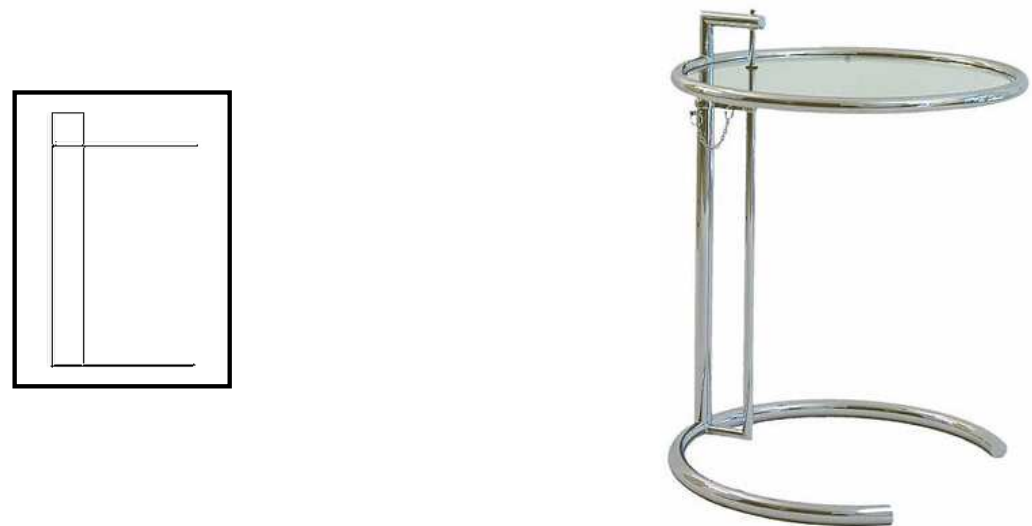

الشكل البنائي

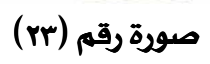

http://www.bauhaus.stars.com : المرجع

\begin{tabular}{|c|c|}
\hline طاوثلة & آشكل \\
\hline زجاج ـ معد ( فولاذ ) & الخخامة \\
\hline 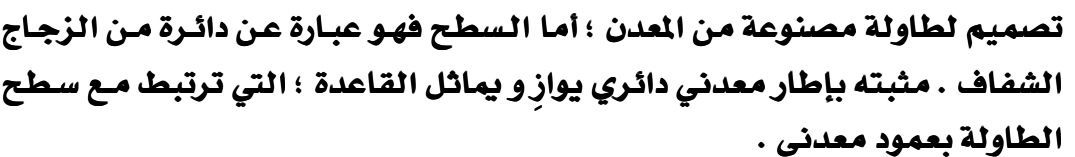 & التوهيف \\
\hline
\end{tabular}




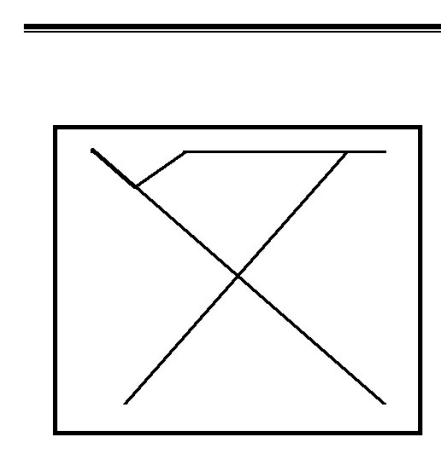

الشكل البنائي

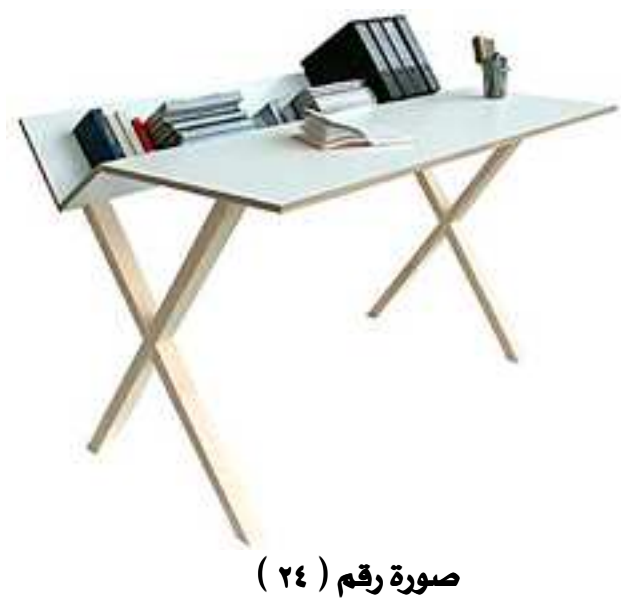

http://Www.arno.org.com : المرجع

\begin{tabular}{|c|c|}
\hline طـاولـة (مكتب) & الشكل \\
\hline خشب. خشب صناعى (أبلاكاج) & الخامة \\
\hline 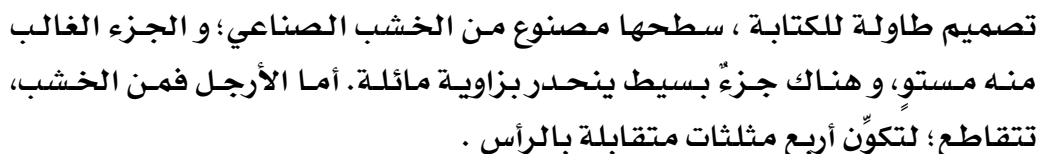 & التوصيف \\
\hline
\end{tabular}

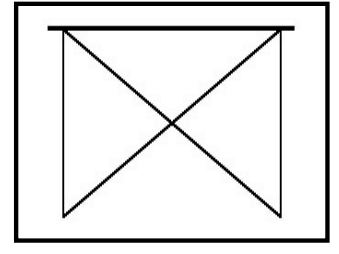

الشكل البنائي

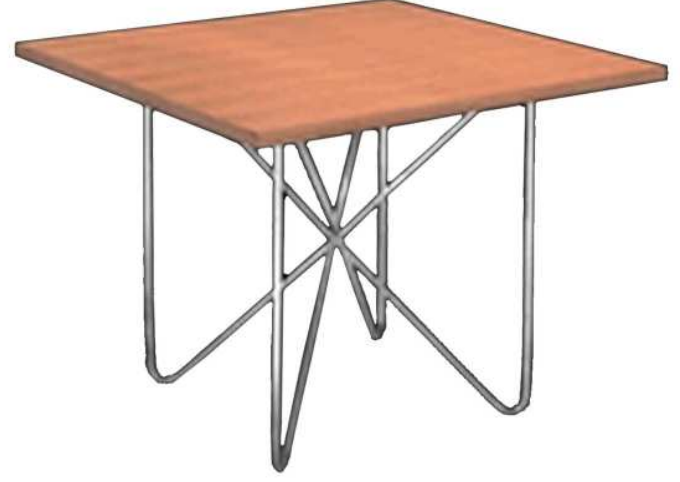

صورة رقم (ro )

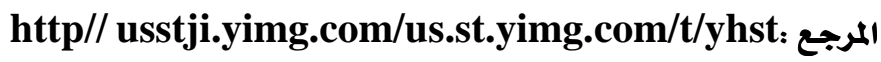

\begin{tabular}{|c|c|}
\hline طاولة & الشكل \\
\hline خشب صناعى - معدن & الخامة \\
\hline 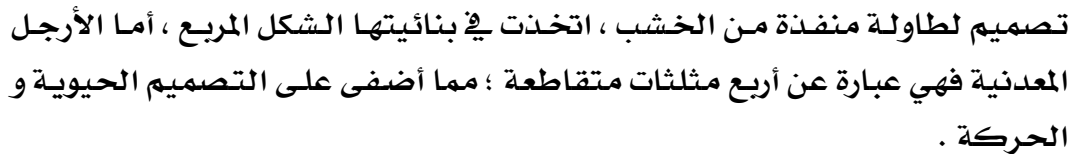 & التوصيف \\
\hline
\end{tabular}




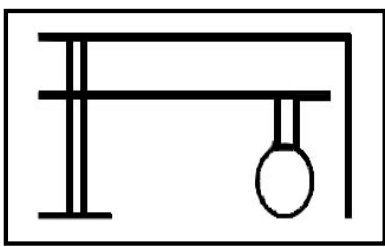

الشكل البنائي

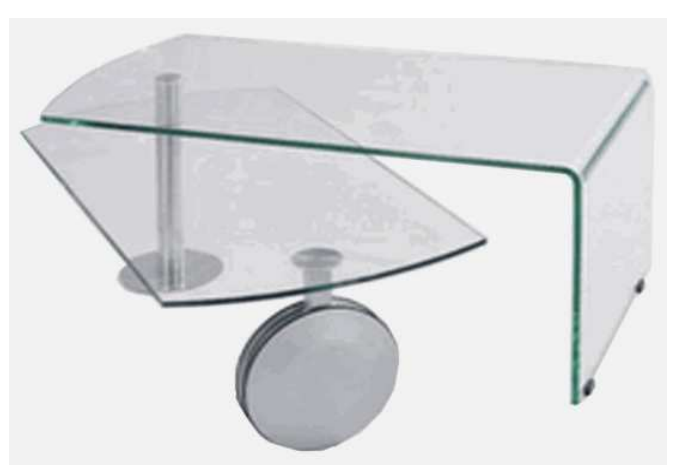

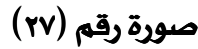

http// usstji.yimg.com/us.st.yimg.com/t/yhst: المرجع

\begin{tabular}{|c|c|}
\hline طاولة & الشكل \\
\hline زجاج - معدن & الخامـة \\
\hline 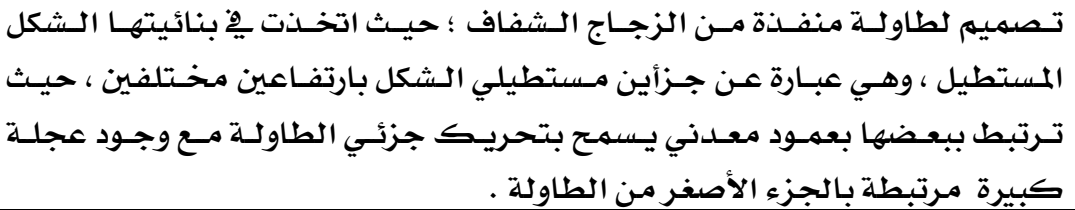 & التوصيف \\
\hline
\end{tabular}

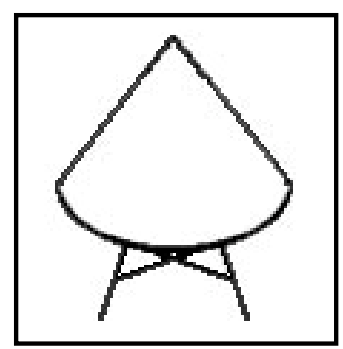

الشكل البنائي

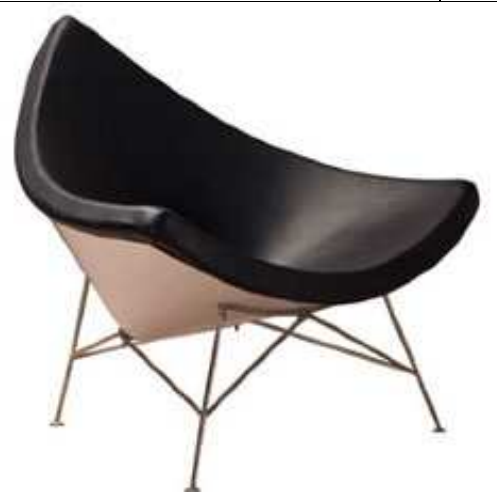

صورة رقم ( ) ( )

http://www.modspace.com: المرجع

\begin{tabular}{|c|c|}
\hline كرسي & الشكل \\
\hline معدن ( فولاذ) _ جلد & الخامة \\
\hline 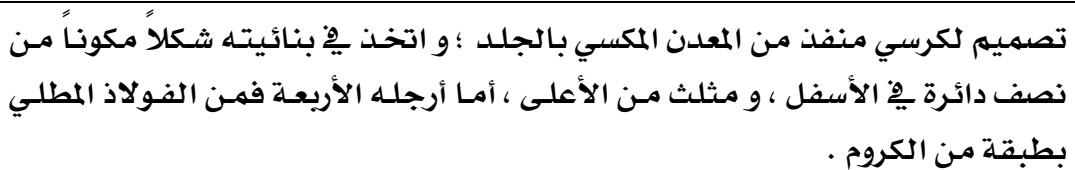 & التوصسيف \\
\hline
\end{tabular}




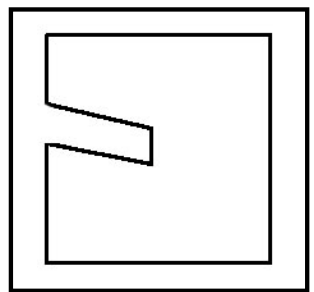

الشكل البنائي

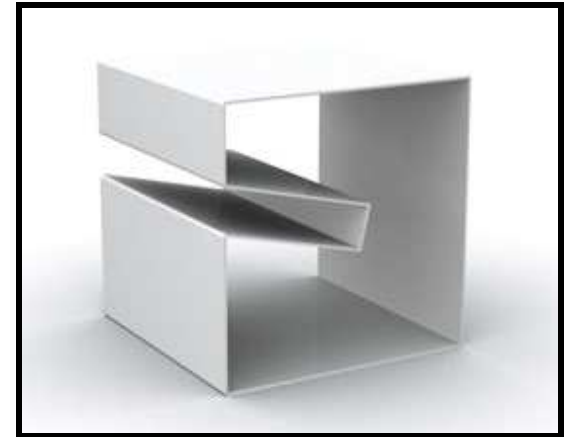

صورة رقم (rr)

http://www.modern .com : المرجع

\begin{tabular}{|c|c|}
\hline طاولـة & الشكل \\
\hline معلدن ( ألومينيوم ) & الخامـة \\
\hline 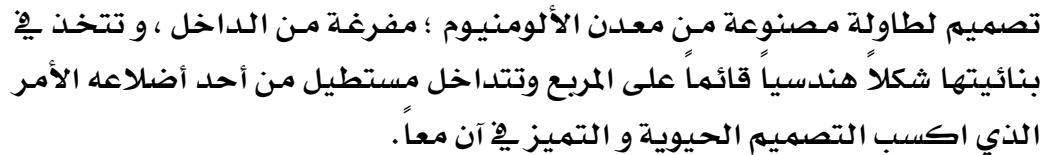 & التوصيف \\
\hline
\end{tabular}

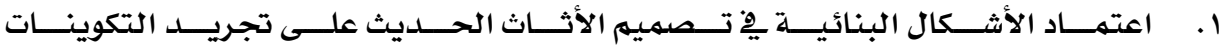
الهندسية لاستنباط تصاميم متتوعة وبسيطة لقطع الأثاث .

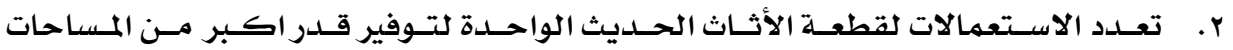

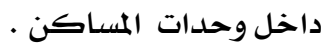

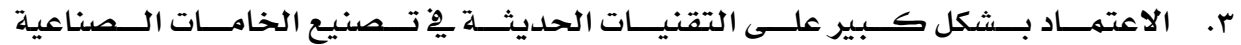

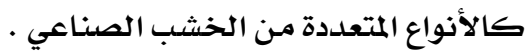

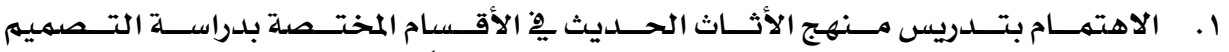

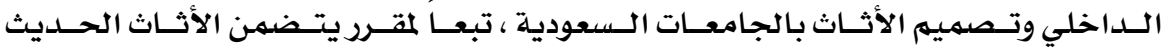

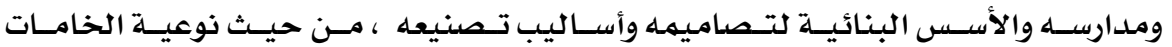
ومميزات وعيوب كل خامـة .

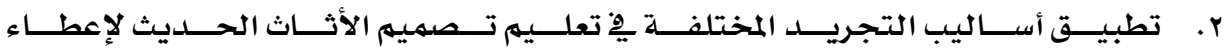
تكوينات وتصاميهم مبتكرة .

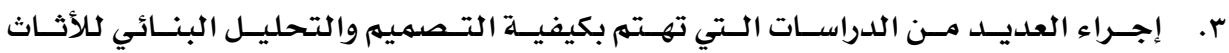
الحديث . إجـاء 


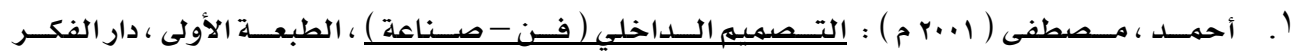

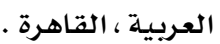

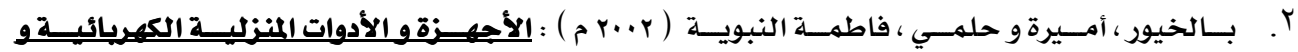

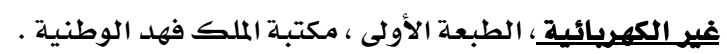

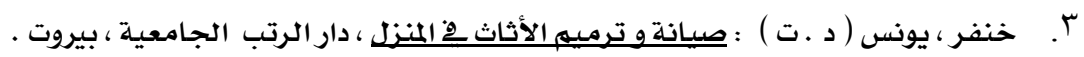

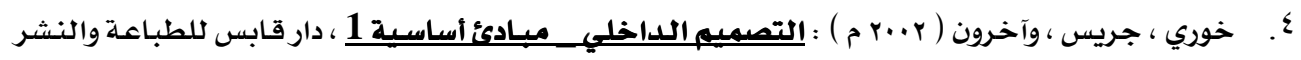

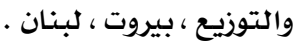

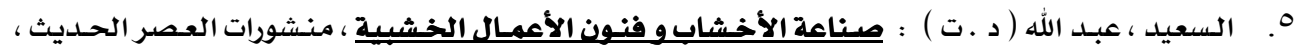
بيروت .

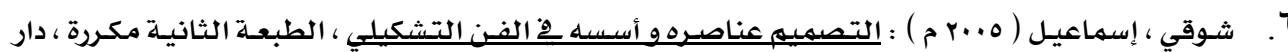

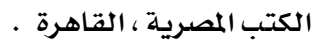

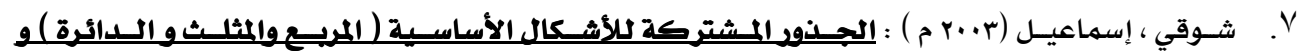

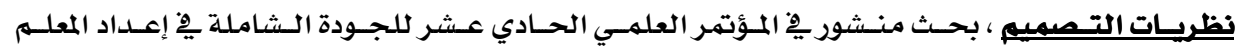

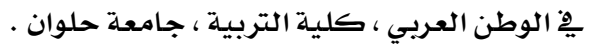

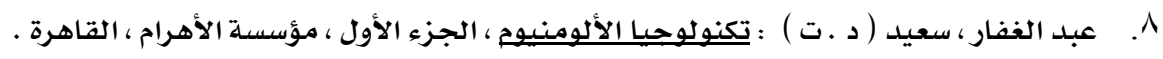

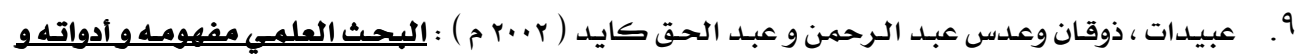

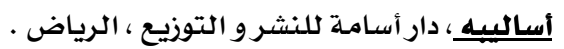

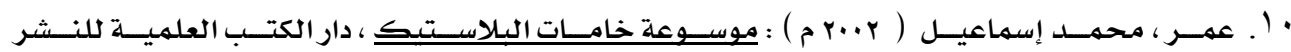

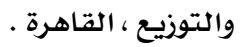
I ا . عيد ، خير الدين ( د ـ ت ) : فنون تشكيل الخشبي ، منشورات العصر الحديث ، بيروت .

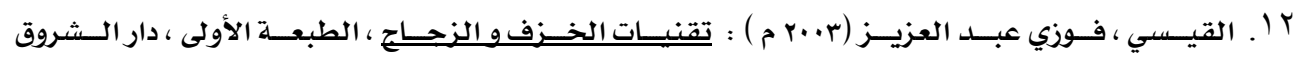

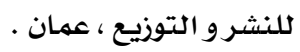

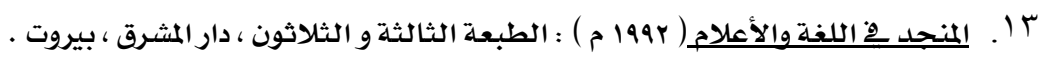

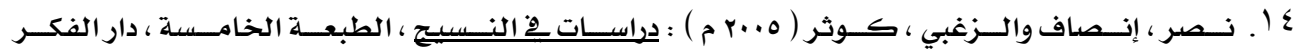

15. Corbett, Stephen ( 2005 ) : The Practical Wood Worker, Anness العربي ، القاهرة . Publishing Limited, London, UK .

16. Pile, John ( 2005 ) : A history of interior design, second edition ,published in by Laurence king publishing ltd , 71 great Russell Street, London, United kingdom .

17. ) Oxford University Press ( 2002) : Eighth Impression, UK . 


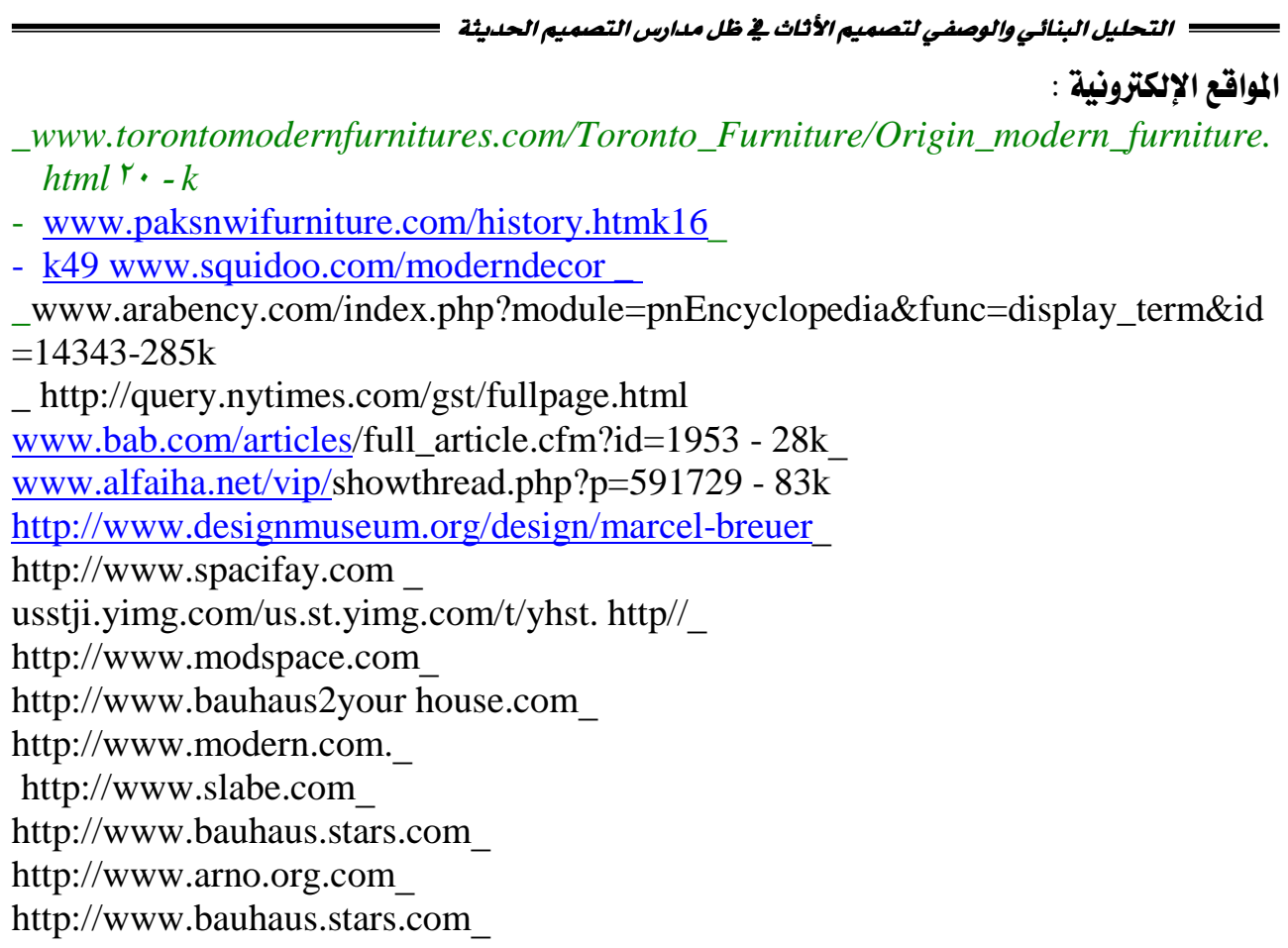

